\title{
A front-end PFC stage for improved performance of flexible induction heating appliances
}

\author{
Mario Pérez-Tarragona*, Héctor Sarnago, Óscar Lucía and José M. Burdío \\ Department of Electronic Engineering and Communications, I3A, Universidad de Zaragoza, C/María \\ de Luna, Zaragoza, Spain
}

\begin{abstract}
Flexible cooking surfaces, eg. fully active surfaces, have gained lately an increasing importance in the domestic induction heating. Multi-inverter structures are a cost-efficient solution to develop this technology. However, they add control restrictions that can be solved with a power factor corrector (PFC) stage as proposed in this work.

The proposed converter and modulation strategy work with zero voltage switching (ZVS), decreasing the switching losses, enabling a higher working frequency and, therefore, decreasing the magnetic devices size. The bus voltage is controllable and can be increased, easing the load power control and decreasing current through load and inverter and, so, the power losses. Besides, the switching frequency is constant in the mains cycle and can be modified to synchronize the load inverter and the PFC stage avoiding intermodulation noise. A $3.6 \mathrm{~kW}$ prototype has been implemented fulfilling the EMC requirements. The experimental waveforms and efficiency have been measured to prove the feasibility of this proposal.
\end{abstract}

Keywords: Power factor corrector, resonant power conversion, zero voltage switching, home appliances, induction heating

\section{Introduction}

In recent years, induction heating $(\mathrm{IH})$ technology has become a reality in our homes [1-5]. This cooking technology has been developed in depth, and it has revolutionized the cooking way. In comparison with typical technologies, such as gas, electric or halogen, IH is more efficient, faster, cleaner and safer [6].

Recently, flexible cooking surfaces have taken importance in the domestic IH technology [7]. There are different types of surfaces with concentric coils or with coils spread along the whole surface, which are denominated fully active surfaces (Fig. 1). These allow heating several pots, no matter the size or shape of these.

The coils from a typical IH cooktop are supplied by an inverter, usually a half-bridge, which is the most common topology in these applications. However, the development of flexible cooking surfaces has brought an increase of the manufacturing cost due to the increased number of coils and power electronics devices. In order to achieve a cost-effective implementation, some multi-inverter structures have been

\footnotetext{
* Corresponding author: Mario Pérez-Tarragona, Departamento de Ingeniería Electrónica y Comunicaciones, Universidad de Zaragoza, María de Luna, 1. 50018 Zaragoza, Spain. Tel.: +34 876 555318; Fax: +34 976 762111; E-mail: maperta@unizar.es.
} 


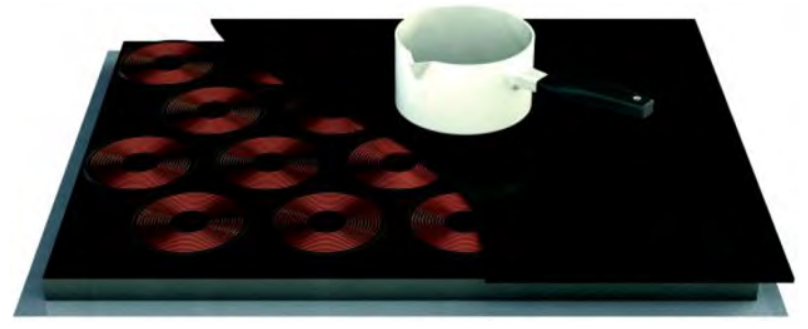

Fig. 1. Fully active surface [17].

proposed recently [8-10]. However, these structures add control restrictions and complicate the power control in the induction loads [2].

In order to overcome these restrictions, a power factor corrector (PFC) front-end stage has been proposed. The PFC stage assures a power factor close to the unity, a low harmonic distortion and generates a controllable DC voltage bus. This stage allows separating the mains front the multi-inverter structure, fulfilling EMC requirements [11-16] and making easier the control of the output power in the pot [1719]. Besides, the bus voltage can be increased, decreasing the current through IH inverter and IH load, and, therefore, decreasing losses in these devices.

Furthermore, having into account that induction heating cooktops with fully active surfaces have usually two isolated electronic board because they are powered from two mains phases, and in order to reduce manufacturing cost implementing multi-inverter struetures, it is interesting to join both electronic boards. This idea can be implemented with a front-end PFC to get a common DC bus. In this way, the total board size and several components such as DC-DC, relays, digital electronic components or heatsinks can be reduced.

The paper is structured as follows. The next section presents the topology of the converter and the operation mode, the control strategy section describes how the converter control is performed. After that section, the implementation and the experimental results are shown and, finally, the main conclusions of this work.

\section{Converter topology and operation mode}

\subsection{Converter topology}

The proposed PFC converter is shown in Fig. 2. It is based on the boost converter and it is composed of two half-bridge legs, a and $\mathrm{b}$, which allow short-circuiting the boost inductance, $L_{b}$, with the mains voltage, $v_{a c}$, with a period $T_{a c}$, and/or the bus voltage, $v_{b}$. Each half-bridge is composed of two switching devices, $S_{h}$ and $S_{l}$, implemented with IGBTs, $T_{h}$ and $T_{l}$, and antiparallel diodes, $D_{h}$ and $D_{l}$. A filter between the mains and the PFC stage is placed, supplying the medium frequency currents and removing the high ripple of the boost coil current, $i_{a c}$. In the proposed implementation, an inductor, $L_{f}$, and a capacitor, $C_{f}$, are used for filtering. Besides, a capacitor, $C_{b}$, filters the bus voltage, which powers the IH inverter. The set is composed of as many half-bridge branches, $S_{h, n}$ and $S_{l, n}$, as IH loads. Each IH load [20] is composed of the series equivalent resistance, $R_{e q, n}$, and inductance, $L_{e q, n}$, and the resonant capacitor, $C_{r, n}$. 


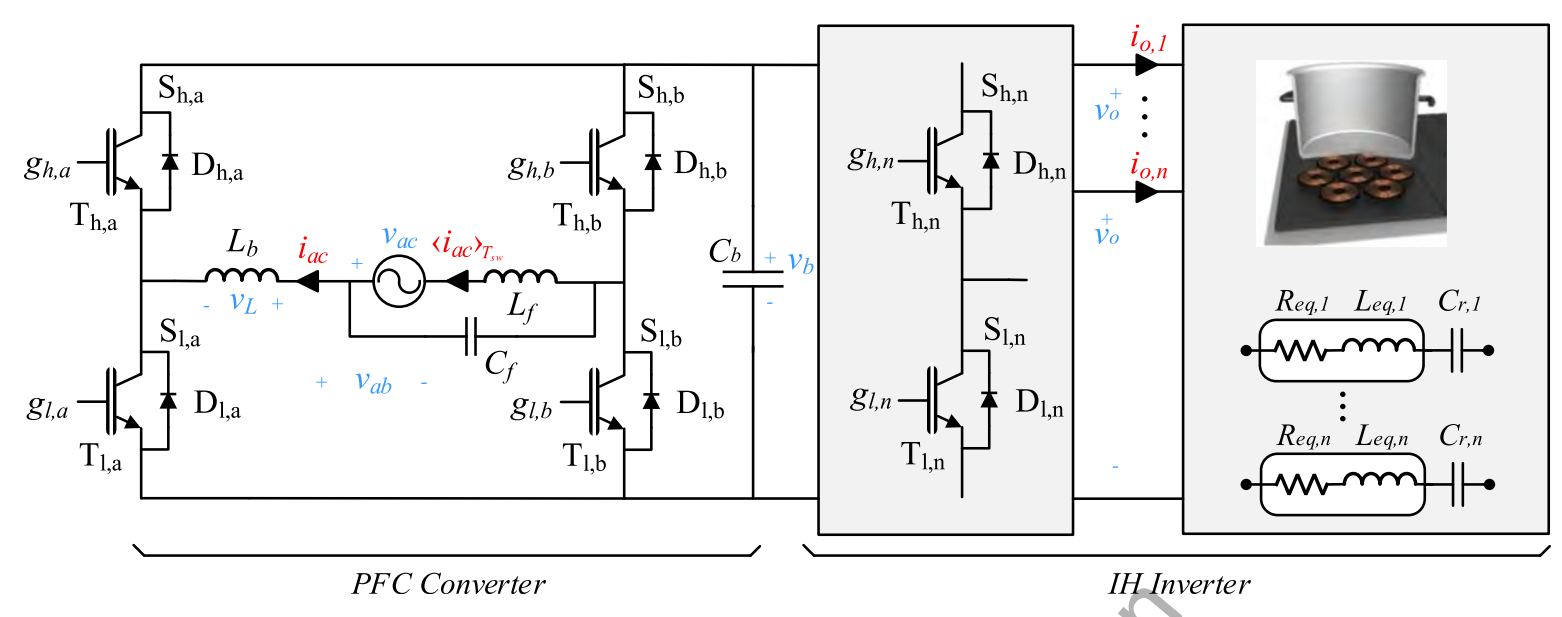

Fig. 2. PFC IH topology with $n$ IH-loads [19].

\subsection{Operation mode}

The PFC converter works in full-bridge configuration in order to get Zero Voltage Switching (ZVS) and fixed-frequency Continuous Conduction Mode (CCM) as is shown in Fig. 3. In this way, the $T_{h, a}$ device and the $T_{l, b}$ device are activated simultaneously, and vice versa. Therefore, the boost voltage, $v_{l}$, according to the activated devices is

$$
v_{L}= \begin{cases}v_{a c}-v_{b}, & T_{h, a}, D_{h, a}, T_{l, b}, D_{l, b}: \text { ON } \\ v_{a c}+v_{b}, & T_{l, a}, D_{l, a}, T_{h, b}, D_{h, b}: \text { ON }\end{cases}
$$

For each branch, the duty cycle can be definedas

$$
D_{a}=\frac{1}{2}\left(1+\frac{v_{a c}}{v_{b}}\right), \quad D_{b}=\frac{1}{2}\left(1-\frac{v_{a c}}{v_{b}}\right) .
$$

This operation mode has several advantages. Firstly, the zero-crossing distortion of the current is avoided because the duty cycle is 0.5 when the mains voltage is zero $\left(v_{a c}=0\right)$, simplifying the converter control and fulfilling EMC requirements. Secondly, this modulation strategy works with ZVS switching, decreasing the switching losses, enabling a higher working frequency, and, therefore, decreasing the value of magnetic devices: the boost inductance and the filter inductance. Besides, the switching frequency is constant along the mains cycle and can be modified to synchronize the load inverter and the PFC stage avoiding intermodulation noise. The main disadvantage is the current through the boost inductance and switching devices of the PFC converter is higher, increasing conduction losses in these components.

\section{Control strategy}

The converter control consists on generating a sinusoidal reference current, $i_{f, r e f}$, in phase with the mains voltage and with the desired RMS current value, $I_{f, r m s}$. The regulator adjusts the mains current, $i_{f}$, to follow the reference exactly. The main advantage of using the control of the current managing the duty cycle, $D_{a}$, is the converter can work at constant frequency avoiding intermodulation noise between IH inverter and PFC stage. This duty cycle must be controlled in order to get a sinusoidal mains current 


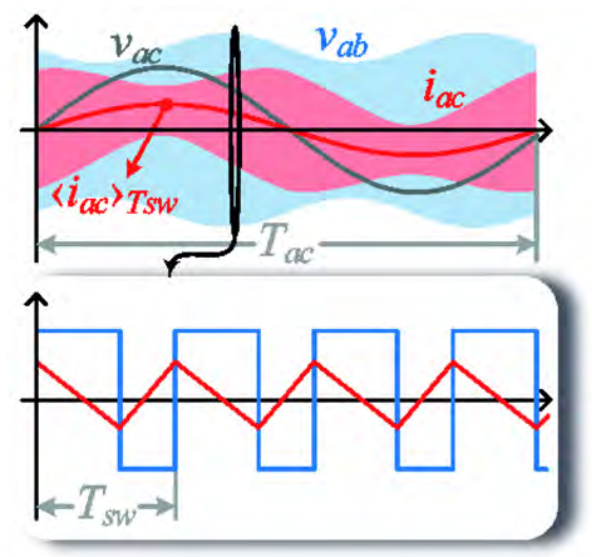

Fig. 3. ZVS and fixed-frequency CCM modulation strategy [17].

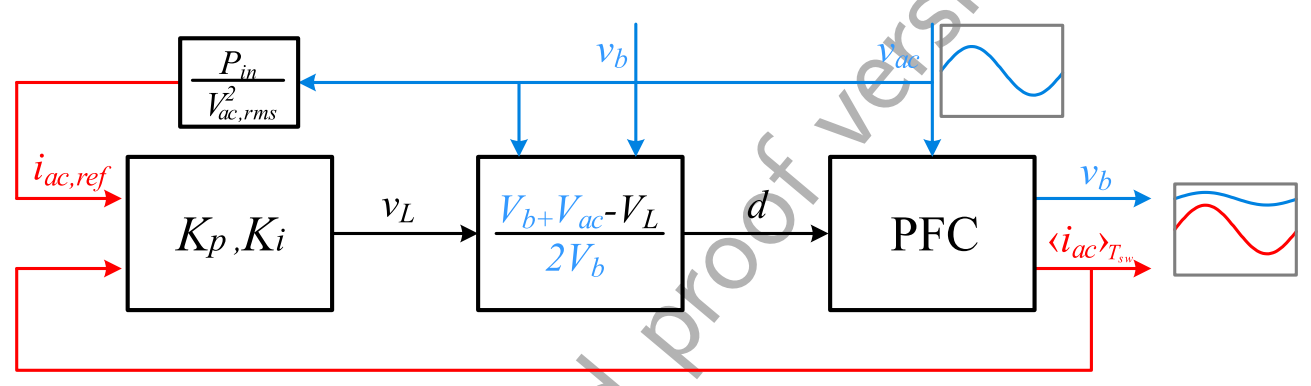

Fig. 4. Control scheme where the calculated action is the boost inductance voltage, $V_{L}$, which is used to calculate later the duty cycle by using the converter parameters [18].

waveform in phase with the mains voltage. In this way, a good power factor and a low total harmonic distortion of the current is achieved.

In order to control the system and to eliminate the stationary error, a proportional, $K_{p}$, and integral, $K_{i}$, regulator is proposed. In typical control schemes, the action calculated by the regulator is directly the duty cycle, $D_{a}$, applied to the PFC stage. However, this system is difficult to control using this scheme because its non-linearity which depends strongly on the mains voltage, the bus voltage, and the induction load.

To overcome this issue, using the boost coil average voltage, $V_{L}$, as controller output action is proposed, as it is shown in Fig. 4. When the average voltage in an inductance differs from zero, it means a lineal variation of its average current according to the differential equation that models the boost coil behavior. Consequently, the $V_{L}$ voltage makes possible to control the boost coil average current, $I_{b}$, linearly and, therefore, the mains current, $i_{f}$, can be properly shaped. Keeping in mind Eq. (2), the duty cycle can be calculated in a second step as

$$
D_{a}=\frac{V_{b}+V_{a c}-V_{L}}{2 V_{b}}, \quad D_{b}=1-D_{a},
$$

where $V_{a c}$ and $V_{b}$ are the mains and the bus average voltage in a switching cycle, respectively.

In order to perform this control, the input voltage, $v_{a c}$, the input current, $i_{f}$, and the bus voltage, $v_{b}$, must be measured. 


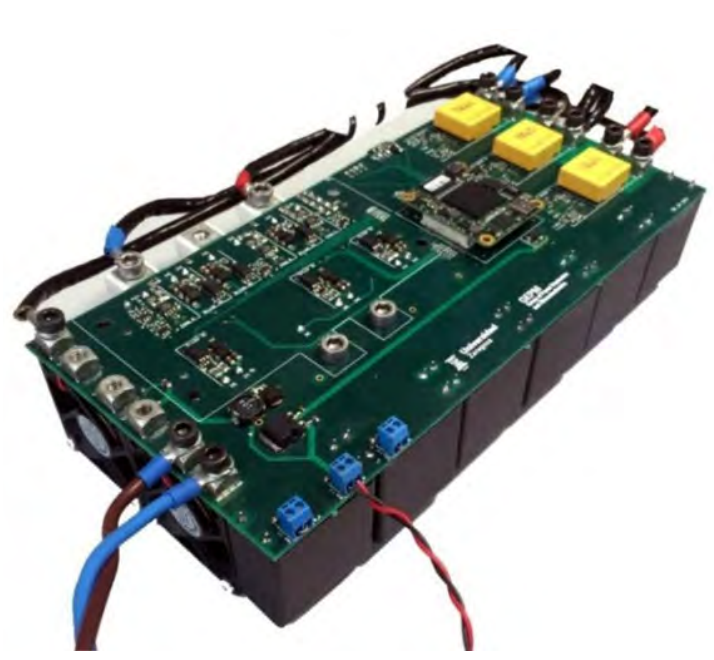

(a)

\begin{tabular}{rl}
\hline \hline PARAMETER & \multicolumn{1}{c}{ VALUE } \\
\hline \hline Mains voltage, $V_{a c, r m s}$ & $230 \mathrm{~V} \mathrm{RMS}, 50 \mathrm{~Hz}$ \\
Input power range & $750-3600 \mathrm{~W}$ \\
Operating frequency range & $20-30 \mathrm{kHz}$ \\
\hline Filter capacitor, $C_{f}$ & $6,6 \mu \mathrm{F}$ \\
Filter coil, $L_{f}$ & $200 \mu \mathrm{H}$ \\
\hline Bus capacitor, $C_{b}$ & $60 \mu \mathrm{F}$ \\
Boost coil, $L_{b}$ & $150 \mu \mathrm{H}$ \\
\hline Resonant capacitor, $C_{r}$ & $536 \mathrm{nF}$ \\
IH-load equivalent inductance, $L_{e q}$ & $170 \mu \mathrm{H}$ \\
IH-load equivalent resistance, $R_{e q}$ & $6 \Omega$ \\
\hline \hline
\end{tabular}

(b)

Fig. 5. Experimental prototype (a) and converter design parameters (b).

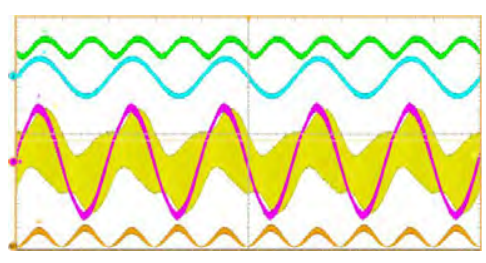

(a)

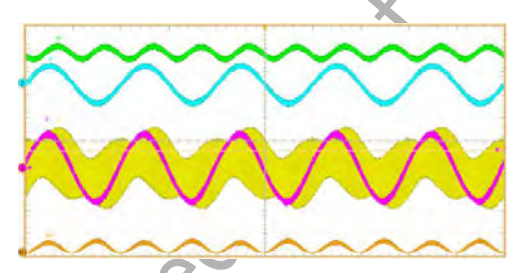

(b)

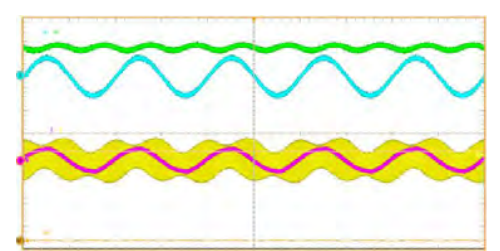

(c)

Fig. 6. Main waveforms of the converter input and PFC stage delivering (a) $3.600 \mathrm{~W}$, (b) $2.300 \mathrm{~W}$ and (c) $750 \mathrm{~W}$ : boost coil current, $i_{b}$, (30 A/div, yellow), mains voltage, $v_{a c}$ (400 V/div, blue), mains current, $i_{f},\left(10 \mathrm{~A} / \mathrm{div}\right.$, purple), bus voltage, $v_{b}$, (400 V/div, green), and input power, $p_{i n},(10 \mathrm{~kW} /$ div, brown $)$. Time: $10 \mathrm{~ms} / \mathrm{div}$.

\section{Implementation and experimental results}

\subsection{Prototype}

In order to prove the feasibility of the proposed topology, a $3.6 \mathrm{~kW}$ prototype with one IH load has been designed and implemented. The operating frequency has been set to be higher than $20 \mathrm{kHz}$ to avoid acoustic noise. The final prototype is shown in Fig. 5. It is composed of a three-phase module, FS150R12PT4, with three half-bridges on parallel using 1200-V Infineon IGBTs. A Spartan-6 FPGA from Xilinx is used to implement the control architecture. Besides, the whole system can be managed from the PC through a Wi-Fi module and a PC application has been developed using Visual Basic.

The $150 \mu \mathrm{H}$ boost inductance, $L_{b}$, and the $200 \mu \mathrm{H}$ filter inductance, $L_{f}$, have been implemented as $10 \mathrm{~cm}$ diameter air core toroids with 43 and 50 loops, respectively. The current is measured with the CDS4050 magneto-resistive current sensors from Sensitec and the voltage is measured using resistive dividers. The analog to digital conversion is performed using a 10-bit and 1-MSPS ADCS7477 converter from Texas Instruments. 


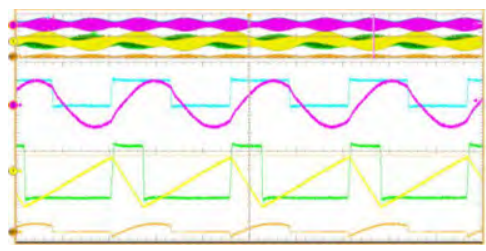

(a)

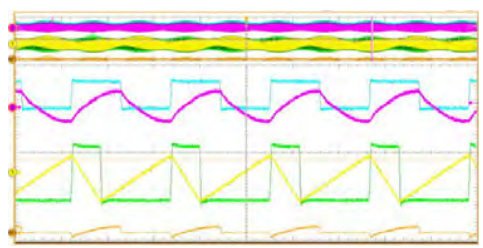

(b)

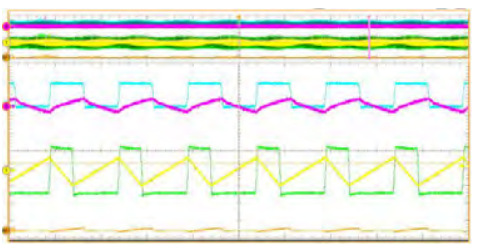

(c)

Fig. 7. Detail of the main waveforms of the converter output and PFC stage delivering (a) $3.600 \mathrm{~W}$, (b) $2.300 \mathrm{~W}$ and (c) 750 W: boost coil current, $i_{b}$, (30 A/div, yellow), load voltage, $v_{o, c}$, $\left(400 \mathrm{~V} /\right.$ div, blue), load current, $i_{l}$, (30 A/div, purple), voltage between a and $\mathrm{b}$ half-bridges, $v_{o, a b}$, $\left(400 \mathrm{~V} / \mathrm{div}\right.$, green), and output power, $p_{\text {out }}$, $(50 \mathrm{~kW} / \mathrm{div}$, brown). Time: $20 \mu \mathrm{s} / \mathrm{div}$.

\subsection{Experimental results}

The experimental results proving the proper operation of the conyerter are shown in Fig. 6 and Fig. 7 at different powers: $3.600 \mathrm{~W}$ in (a), $2.300 \mathrm{~W}$ in (b) and $750 \mathrm{~W}$ in (c), with a $400-\mathrm{V}$ DC bus voltage. The main waveforms of the PFC stage are shown in Fig. 6, including the bus voltage, $v_{b}$, the mains voltage, $v_{a c}$, the boost coil current, $i_{b}$, and the mains current, $i_{f}$, whereas a zoomed detail of the load and PFC stage waveforms are shown in Fig. 7. The ZVS operation can be seen for both cases.

At maximum power, the converter is working at $20.5 \mathrm{kHz}$ achieving a $92.5 \%$ efficiency. The EMC harmonic emissions for A-class devices are below the maximum limit. The achieved power factor is $99.7 \%$ while the current harmonic distortion, THDi, is $2.9 \%$.

\section{Conclusions}

In this paper, a PFC front-end stage, its operation mode and its control strategy have been proposed to improve the flexible cooking surfaces. This stage allows controlling and increasing the bus voltage, easing the output power control and decreasing the power losses in the IH inverter due to the current through the IH load and inverter is lower.

The proposed operation mode and control strategy work with zero voltage switching (ZVS), decreasing the switching losses, enabling a higher working frequency and, therefore, decreasing the magnetic devices size. Besides, the switching frequency is constant in the mains cycle and can be modified to synchronize the load inverter and the PFC stage avoiding intermodulation noise. Finally, a $3.6 \mathrm{~kW}$ prototype has been implemented fulfilling EMC requirements and proving the feasibility of this proposal.

\section{Acknowledgements}

This work has been partially funded by the MINECO under the Project TEC2016-78358-R, by the Spanish MICINN and AEI under Project RTC-2017-5965-6, co-funded by EU through FEDER program, by the DGA-FSE, by the BSH Home Appliances Group, and by the Spanish MECD under the FPU grant FPU15/01590. 


\section{References}

[1] O. Lucía, P. Maussion, E. Dede and J. M. Burdío, Induction heating technology and its applications: Past developments, current technology, and future challenges, IEEE Transactions on Industrial Electronics 61 (2014), 2509-2520, doi:10.1109/TIE.2013.2281162.

[2] M. Nakagawa and H. Yonemori, A study on the audible frequency area noise emanating from a pan when the IH cooker is fed by the power source including harmonics, International Journal of Applied Electromagnetics and Mechanics 59 (2019), 1421-1430, doi:10.3233/jae-171236.

[3] L. Qiu, X.B. Wen, H.S. Li and T.G. Li, Study on effect of material property on thermal power in induction cooker system with finite element method, International Journal of Applied Electromagnetics and Mechanics 46 (2014), 35-42, doi:10.3233/jae-141744.

[4] H. Sarnago, O. Lucia, A. Mediano and J. M. Burdio, Analysis and design of high-efficiency resonant inverters for domestic induction heating applications, International Journal of Applied Electromagnetics and Mechanics 44 (2014), 201-208, doi:10.3233/jae-141760.

[5] H.C. Chen and K.H. Huang, Finite element analysis of coupled electromagnetic and thermal fields within a practical induction heating cooker, International Journal of Applied Electromagnetics and Mechanics 28 (2008), 413-427, doi:10.3233/jae-2008-994.

[6] H. Sarnago, A. Mediano and O. Lucía, High efficiency ac-ac power electronic converter applied to domestic induction heating, IEEE Transactions on Power Electronics 27 (2012), 3676-3684, doi;10.1109/TPEL.2012.2185067.

[7] Ó. Lucía, J. Acero, C. Carretero and J.M. Burdío, Induction heating appliances: Towards more flexible cooking surfaces, IEEE Industrial Electronics Magazine 7 (2013), 35-47, doi:10.1109/MIE.2013.2247795.

[8] H. Sarnago, J.M. Burdio and O. Lucia, High-performance and cost-effective ZCS Matrix resonant inverter for total active surface induction heating appliances, IEEE Transactions on Power Electronics 34 (2019), 117-125, doi:10.1109/tpel.2018.2815902.

[9] O. Lucía, J.M. Burdío, L.A. Barragán, J. Acero and I. Millán, Series-resonant multiinverter for multiple induction heaters, IEEE Transactions on Power Electronics 24 (2010), 2860-2868, doi:10.1109/TPEL.2010.2051041.

[10] H.N. Pham, H. Fujita, K. Ozaki and N. Uchida, Dynamic analysis and control for resonant currents in a zone-control induction heating system, IEEE Transactions on Power Electronics 28 (2013), 1297-1307, doi:10.1109/tpel.2012.2210286.

[11] M.M. Jovanovic and Y. Jang, State-of-the-art, single-phase, active power-factor-correction techniques for high-power applications - an overview, IEEE Transactions on Industrial Electronics 52 (2005), 701-708, doi:10.1109/TIE.2005.843964.

[12] L. Huber, B.T. Irving and M.M. Jovanovic, Effect of valley switching and switching-frequency limitation on line-current distortions of DCM/CCM boundary boost PFC converters, IEEE Transactions on Power Electronics 24 (2009), 339-347, doi:10.1109/TPEL.2008.2006053.

[13] J. Biela, D. Hassler, J. Miniböck and J. W. Kolar, Optimal design of a $5 \mathrm{~kW} / \mathrm{dm}^{3} / 98.3 \%$ efficient TCM resonant transition single-phase PFC rectifier, in: The 2010 International Power Electronics Conference - ECCE ASIA, 2010, pp. 1709-1716.

[14] F.Z. Chen and D. Maksimovi, Digital control for improved efficiency and reduced harmonic distortion over wide load range in boost PFC rectifiers, IEEE Transactions on Power Electronics 25 (2010), 2683-2692, doi:10.1109/TPEL.2010.2050702.

[15] M. Hartmann and J.W. Kolar, Analysis of the trade-off between input current quality and efficiency of high switching frequency PWM rectifiers, in: Power Electronics Conference (IPEC), 2010 International, 2010, pp. 534-541.

[16] C. Marxgut, J. Biela and J.W. Kolar, Interleaved triangular current mode (TCM) resonant transition, single phase PFC rectifier with high efficiency and high power density, in: Power Electronics Conference (IPEC), 2010 International, 2010, pp. $1725-1732$

[17] M. Pérez-Tarragona, H. Sarnago, Ó. Lucía and J.M. Burdío, Design and experimental analysis of PFC rectifiers for domestic induction heating applications, IEEE Transactions on Power Electronics 33 (2018), 6582-6594, doi:10.1109/TPEL.2017.2755367.

[18] M. Pérez-Tarragona, H. Sarnago, Ó. Lucía and J.M. Burdío, Active Power Factor Corrector for High Power Domestic Induction Heating Appliances, in: IEEE Annual Conference of the Industrial Electronics Society, 2017, pp. 3779-3784.

[19] M. Pérez-Tarragona, H. Sarnago, Ó. Lucía and J.M. Burdío, Soft-transient modulation strategy for improved efficiency and EMC performance of PFC converters applied to flexible induction heating appliances, in: 2018 IEEE Applied Power Electronics Conference and Exposition (APEC), 2018, pp. 3530-3534.

[20] H. Sarnago, O. Lucía and J. M. Burdio, A versatile resonant tank identification methodology for induction heating systems, IEEE Transactions on Power Electronics 33 (2018), 1897-1901, doi:10.1109/TPEL.2017.2740998. 